\title{
The role of the nose in snoring and obstructive sleep apnoea: an update
}

\author{
Christos Georgalas
}

Received: 9 September 2010/Accepted: 10 December 2010/Published online: 22 February 2011

(C) The Author(s) 2011. This article is published with open access at Springerlink.com

\begin{abstract}
Multilevel anatomic obstruction is often present in snoring and obstructive sleep apnoea (OSA). As the nose is the first anatomical boundary of the upper airway, nasal obstruction may contribute to sleep-disordered breathing (SDB). A number of pathophysiological mechanisms can potentially explain the role of nasal pathology in SDB. These include the Starling resistor model, the unstable oral airway, the nasal ventilatory reflex and the role of nitric oxide (NO). Clinically, a number of casecontrol studies have shown that nasal obstruction is associated with snoring and mild SDB. However, there is not a linear correlation between the degree of nasal obstruction and the severity of SDB, while nasal obstruction is not the main contributing factor in the majority of patients with moderate to severe OSA. Randomised controlled studies have shown that in patients with allergic rhinitis or nonallergic rhinitis and sleep disturbance, nasal steroids could improve the subjective quality of sleep, and may be useful for patients with mild OSA, however, they are not by themselves an adequate treatment for most OSA patients. Similarly, nasal surgery may improve quality of life and snoring in a subgroup of patients with mild SDB and septal deviation, but it is not an effective treatment for OSA as such. On the other hand, in patients who do not tolerate continuous positive airway pressure (CPAP) well, if upper airway evaluation demonstrates an obstructive nasal passage, nasal airway surgery can improve CPAP compliance and adherence.
\end{abstract}

C. Georgalas $(\bowtie)$

Otolaryngology Department, Academic Medical Center, Meibergdreef 9, 1105 AZ Amsterdam, The Netherlands e-mail: c.georgalas@amc.nl; cgeorgalas1@yahoo.co.uk
Keywords Sleep-disordered breathing .

Obstructive sleep apnoea - Nasal disease - Rhinitis .

Chronic rhinosinusitis - Nasal septum deviation - CPAP

\section{Introduction}

Hippocrates in "de Morbis Popularibis" (П $\varepsilon \rho '$ $\left.\mathrm{E} \pi \imath \delta \eta \mu \imath \omega^{\prime} v\right)$ noted that nasal polyps were associated with restless sleep [1]. Indeed, most people have experienced sleeping difficulty during episodes of virally induced nasal congestion. Hence, a link between nasal breathing and sleep as well as improvement of sleep quality following relief of nasal obstruction would seem intuitive. However, the literature is not conclusive in that respect despite the interest in the area, as demonstrated by the number of relevant articles published. Nevertheless, our understanding of nasal and sleep physiology and particularly of the importance of nasal and oral breathing as relating to sleep apnoeas and total airway resistance has significantly progressed over the last decade, while recent double-blind randomised controlled trials evaluating treatment outcomes objectively and the use of quality of life (QoL) outcome instruments have further added to our knowledge.

Sleep apnoea is usually defined as cessation of air flow into the lungs which lasts for more than $10 \mathrm{~s}$. The severity of sleep apnoea is defined primarily by the apnoea/hypopnoea index (AHI) - the number of apnoeas (cessation of airflow for more than $10 \mathrm{~s}$ ) and hypopneas (variable definitions, usually significant decrease in airflow) per hour [2]. Sleep-related breathing disorder (SRBD) is essentially a disease continuum ranging from simple or primary snoring at one end to obstructive sleep apnoea (OSA) at the other [3]. Upper airway resistance syndrome (UARS) occupies an intermediate position in this spectrum. The prevalence 
of primary/simple snoring in middle-aged men is in the range of $25-50 \%$ [4], whereas significant sleep-disordered breathing affects up to $8 \%$ of males and $3 \%$ of females [5] (as shown in the recent prospective Sleep Heart population study in 6,441 subjects). Dynamic MRI imaging, acoustic analysis, sedation endoscopy and pharyngeal luminal pressure recordings have established the fact that both snoring and OSA are multilevel phenomena [6-10] whereby turbulent airflow is associated with obstruction in the naso, oro and hypopharynx in differing proportions in individual patients. As the nose constitutes the first port of entry of inspired air under normal conditions, nasal pathology has a significant impact on air flow and hence, potentially contribute to SRBD $[11,12]$.

\section{Effects of nasal obstruction on breathing during sleep}

The nose accounts for more than $50 \%$ of the total resistance of the upper airway and nasal breathing serves important physiological functions, including humidification, heating and filtration [13]. Physiological mechanisms that explain the relationship between nasal airflow and breathing during sleep include the Starling resistor model, the unstable oral airway proposition, the nasal ventilatory reflex and the role of nitric oxide (NO) (Table 1).

The Starling resistor model [14, 15] (Fig. 1) views the upper airway as a hollow tube, with a partial obstruction at the inlet (corresponding to the nose) and a collapsible segment downstream, corresponding to the oropharynx. This model predicts that a further obstruction upstream (nose) will generate a suction force (negative intraluminal pressure) downstream (oropharynx) resulting, in predisposed individuals, in oropharyngeal collapse. This effect is exacerbated at the supine position, when nasal resistance tends to increase both actively due to postural reflex mechanisms as well as passively as a result of the reduced hydrostatic pressure on nasal venous circulation [16].

One can argue that this model fails to take into account a major feature of normal breathing, namely oral breathing bypass, the option of mouth breathing when nasal resistance exceeds a certain level. However, this switch (from

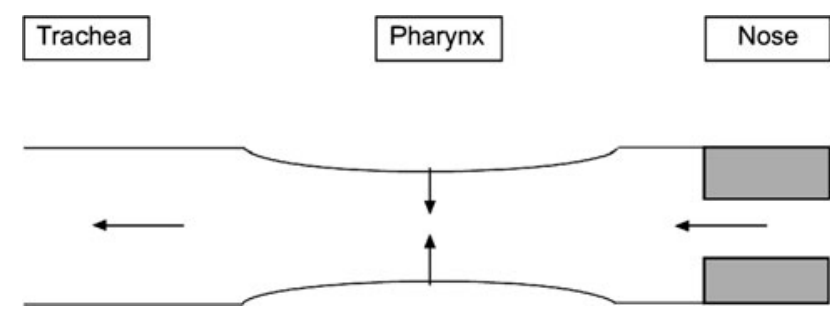

Fig. 1 The Starling resistor model of upper airway collapsibility. The upper airway behaves like a Starling resistor in that obstruction at the inlet (i.e. the nasal airway) produces collapsing forces that are manifest downstream in the collapsible segment, the pharynx

nasal breathing to oral breathing) is physiologically disadvantageous and results in unstable oral breathing. During sleep, upper airway resistance is lower in subjects breathing through the nose than that through the mouth, unlike awake state, during which upper airway resistance is the same in nasal or oral breathing [17]. Hence, the fraction of oral breathing normally decreases during sleep from 7.6 to $4.3 \%$ [18]. When the nasal airway is almost completely obstructed, a switch from nose to mouth breathing occurs, but at a high physiological cost. Mouth breathing is associated with up to 2.5 times higher total resistance [17] and with narrowing of the pharyngeal lumen, decrease in the retroglossal diameter as a result of further posterior retraction of the tongue and increase in the oscillation of the soft palate and redundant pharyngeal tissue [19], all factors leading to SRDB.

A third factor is nasal-ventilator reflex. Experimental application of local anaesthetics to the nasal mucosa of healthy volunteers leads to a significant increase of both central and obstructive apnoeic episodes, of the same magnitude to those reported with complete nasal obstruction [20]. Similar results from other experiments [21] confirmed that the activation of nasal receptors during nasal breathing has a direct positive effect on spontaneous ventilation resulting in higher resting breathing frequency and minute ventilation. Bypassing the nasal airway can lead to reduced nasal receptor activation, deactivation of the nasal-ventilatory reflex and reduced spontaneous ventilation which, in a subset of susceptible individuals can be associated with exacerbating or unmasking previously

Table 1 Pathophysiology of nasal function in the pathogenesis of OSA

\begin{tabular}{lc}
\hline a. Starling resistor model & $\begin{array}{c}\text { Elevated nasal resistance upstream results in increased negative pressure (suction force) in oropharyngeal } \\
\text { airway downstream }\end{array}$ \\
b. Unstable oral breathing & $\begin{array}{c}\text { Significantly increased nasal airway resistance results in compensatory increase of oral breathing fraction } \\
\text { and switching to breathing through an unstable oral airway, resulting in increased total airway resistance }\end{array}$ \\
c. Nasal-ventilatory reflex & $\begin{array}{c}\text { Decreased nasal airflow results in decreased activation of nasal receptors with subsequent inhibitory action } \\
\text { on muscle tone, breathing frequency and minute lung ventilation }\end{array}$ \\
Decreased nasal flow results to reduced lung NO with resultant potential perfusion ventilation mismatch \\
as well as various effects on oropharyngeal musculature and arousals
\end{tabular}


subclinical sleep apnoea [22], as well as increasing the duration of apnoeic episodes [23].

Finally NO is thought to play a role in maintaining upper airway patency by acting as an aerotransmitter between the nose, pharyngeal musculature and the lung [24]. NO is produced in significant amounts in the nose and sinuses and has been shown to be (and used clinically as) a potent lung vasodilator, reducing perfusion-ventilation mismatch and improving overall blood oxygenation [25]. As the total amount of inspired NO varies accordingly to nasal flow [26], it seems logical that a decrease of nasal ventilation would result in reduced NO delivery to the lungs and a reduced oxygen exchange capability. However, NO has also a role in the maintenance of muscle tone and the regulation of neuromuscular pathways in the pharyngeal musculature as well as spontaneous breathing and sleep regulation, so, overall, its role in the nasal regulation of OSA although probably quite significant, is still not completely understood [27].

\section{Clinical and experimental evidence of correlation between nasal pathology and SDB}

Several lines of evidence suggest that experimental reduction of nasal patency and flow has a significant effect on breathing during sleep. In one study, intranasal application of petroleum jelly gauzes in healthy volunteersinduced obstructive apnoeic episodes and resulted in significant increases in $\mathrm{AHI}$, producing frank OSA in one subject [28]. In another study, artificially induced complete or partial nasal obstruction resulted in significant alteration of sleep pattern, with increased micro arousals and total number of apnoeas [29]. In a clinical setting, a number of studies have shown that the application of nasal packs during the management of epistaxis results in significantly worse quality of sleep with multiple apnoeas and desaturation episodes [12, 30-32]. Hence, it is probably safe to conclude that artificially induced partial or complete nasal obstruction results in increased sleep apnoeas.

Nasal obstruction experienced by patients could be due to structural abnormalities (e.g. deviated nasal septum, enlarged turbinates and nasal valve collapse), inflammatory mucosal disease (rhinitis, chronic rhinosinusitis with or without nasal polyps) or more rarely due to neuromuscular problems. Numerous observational studies have demonstrated that nasal congestion is associated with snoring and daytime sleepiness: Wisconsin Sleep Study, a prospective population study of 1,032 healthy volunteers, showed a threefold increased incidence of snoring and day time sleepiness in volunteers with self-reported nocturnal nasal congestion [33], while a study of 37 patients assessed with polysomnography and rhinomanometry showed a correlation between nasal resistance in the supine position and habitual snoring [34]. On the other hand, Lofaso et al. [35] in a prospective study showed that nasal obstruction as documented by posterior rhinomanometry in the awake state is an independent risk factor for OSA, albeit accounting for only $2.3 \%$ of the total AHI variance. These results have been contradicted by some other studies including the study by Miljeteig et al. [36], who divided 683 patients referred for sleep polysomnography in three groups, on the basis of their nasal resistance. He subsequently failed to find any differences in apnoea and snoring indices between the three groups [36]. However, the study assessed awake nasal resistance in the erect position, while, as the authors noted themselves, it seems more likely that sleep disturbances correlate with supine nasal obstruction during sleep. The same authors performed a few years later a similar study measuring supine nasal resistance and again failed to find any correlation with Sleep Disturbance indices, however, their study did not include patients with significant nasal obstruction, while all the measurements were done in non-physiologic conditions, with the subjects having their mouths taped (!) throughout the night to prevent oral breathing [37].

Epidemiological studies [38] have shown that allergic rhinitis (AR) affects $9-42 \%$ of the population. The mechanism by which allergic rhinitis causes poor sleep quality and daytime fatigue is not entirely clear but it is thought that multiple factors are involved. Apart from nasal obstruction, various inflammatory mediators such as IFN-g, TNF-a, IL-1b, IL-4, and IL-10 [39, 40], postural changes and some therapeutic agents such as antihistamines may also have a direct effect on sleep regulation. In patients with AR a direct association between nasal resistance and SRDB severity has been found [41] as well as between nasal obstruction and subjective quality of sleep and daytime sleepiness [42]. A recent study found that both AR and non-allergic rhinitis (NAR) are associated with impaired sleep quality, with up to $83 \%$ of NAR patients having sleep complaints [43].

In a recent overview McNicholas [44] tried to synthesise these apparently conflicting results, pointing out that reversible nasal obstruction maybe more closely associated with SRDB than permanent nasal obstruction, noting that studies assessing patients with temporal obstruction (including iatrogenic and allergic rhinitis) tended to show a more consistent association with SDB than studies assessing patients with structural abnormalities such as deviated nasal septum.

In conclusion, it appears that nasal obstruction, especially reversible, either artificial or disease-induced, is associated with snoring and mild SDB. However, a direct correlation between the degree of nasal obstruction and the severity of SDB has not been found and certainly, nasal 
obstruction does not appear to be the main contributing factor in the majority of patients with moderate to severe OSA.

\section{Management options}

Introduction—problems with research

Nasal pathology associated with nasal obstruction can be treated medically (nasal steroids, antihistamines, decongestants, leukotriene antagonists and nasal dilators) or surgically. Although a number of clinical trials have assessed the effectiveness of the above, they lacked uniformity and only a handful had objective outcome measures. Many of the studies were non-randomised, lacked a control group, had small number of patients and short follow-up periods.

Another problem in many of the studies assessing the efficacy of these treatments, was the lack of clear inclusion criteria. In many studies that was just self-reported nasal obstruction, while in others it was physician's assessment. On the other hand, the use of objective criteria for nasal obstruction (such as rhinomanometry or acoustic rhinometry) must take into account the unreliable correlation between what these studies measure and what the patient experiences as nasal obstruction. Finally, the results of studies on the effectiveness of medication on nasal pathology (such as allergic rhinitis) assess the effect of treating the underlying disease and not the effect of treating nasal obstruction as such.

\section{Medical treatment}

In patients with chronic rhinitis the main cause of high nasal resistance is excessive swelling and engorgement of nasal mucosa. In terms of conservative treatment this could be overcome by topical steroids, sympathomimetic decongestants, or (in the case of AR), by antihistamines and leukotriene antagonists.

Nasal steroids

\section{Randomised trials}

There are four double-blind randomised controlled studies assessing the efficacy of nasal steroids on sleep quality in patients with allergic rhinitis [45-48] (Table 2). Only one of these, however, had objective outcome measures and included OSA patients [47], while the other three studies [45, 46, 48] included patients with self-described poor quality of sleep. These three studies were performed using the same methodology, selection criteria and outcomes but with different nasal steroids. Their results have been pooled and presented together by the authors in 2005 [49]. In summary, they showed that patients with Skin Prick Test proven perennial allergic rhinitis had subjective improvement in their quality of sleep as well as reduced daytime sleepiness following treatment with nasal steroids, and this improvement correlated with improvement of nasal patency. In the one [46] where sleep studies were performed they showed no significant change in AHI or any other objectively measured sleep parameter. The fourth trial by Kiely et al. [47] was performed in both NAR and AR patients and also showed improvement in subjective sleep quality in non-OSA patients but not in patients with frank sleep apnoea. Rather contradictorily, it showed a slight reduction of the AHI (by a mean of 6.5 points, from a median of 20 down to 13 episodes per hour), however, most patients continued to have significant OSA.

In conclusion, in patients with AR or NAR and sleep disturbance, nasal steroids improve the subjective quality of sleep, however, although they maybe be useful as an adjunct for patients with mild OSA, they are an inadequate treatment for most OSA patients.

\section{Decongestants}

\section{Randomised controlled trials}

Three RCTs have been performed on the use of nasal decongestants (oxymetazoline) in OSA: In the first of these studies [50] the decongestant was combined with an internal nasal valve dilator, in the second one with an external dilator (Breath Right ${ }^{\mathrm{TM}}$ ) [51] while a more recent study assessed the effect of decongestant alone [52]. The characteristics and results of the studies are also presented in Table 2. Two of the three RCTs showed no change in AHI and sleep architecture, while the study by McLean showed a modest decrease in AHI of limited clinical significance but no improvement in sleep quality or daytime somnolence. On the other hand, the study by Clarenbach showed no improvement in either subjective or objective indices of AHI. However, it did show that at the time of maximal effect of oxymetazoline there was a significant reduction in AHI, while the study by Kerr demonstrated subjective improvements in sleep quality.

Taken together, these results would show that although nasal decongestants with or without nasal dilators are not effective in the management of OSA (no improvement in sleepiness or AHI). In any case, their use is limited for only a few days, and hence, they could never be advocated for the management of OSA. 
Table 2 Randomised controlled studies assessing nasal pharmacological interventions for sleep disturbance

\begin{tabular}{|c|c|c|c|c|c|c|c|}
\hline References & Study design & Patients & $\begin{array}{l}\text { Nasal } \\
\text { pathology }\end{array}$ & Intervention & Objective outcomes & $\begin{array}{l}\text { Subjective } \\
\text { outcome }\end{array}$ & Notes \\
\hline $\begin{array}{l}\text { Kiely et al. } \\
{[47]}\end{array}$ & $\begin{array}{l}\text { Double blind } \\
\text { crossover } \\
\text { RCT }\end{array}$ & $\begin{array}{l}10 \text { simple } \\
\text { snorers (mean } \\
\text { AHI:3), } 13 \\
\text { OSA patients } \\
\text { (mean AHI: } \\
\text { 26.5) }\end{array}$ & $\begin{array}{l}\text { PAR or SAR, } \\
\text { no septal } \\
\text { deviation }\end{array}$ & $\begin{array}{l}\text { Fluticasone } \\
100 \text { mcg bd for } \\
4 \text { weeks }\end{array}$ & $\begin{array}{l}\text { Median AHI reduced } \\
\text { in OSA patients } \\
\text { taking fluticasone } \\
\text { from } 30.3 \text { to } 23.0 \\
(p<0.001)\end{array}$ & $\begin{array}{l}\text { Improvement } \\
\text { daytime } \\
\text { alertness for } \\
\text { non-apnoeic } \\
\text { patients, not } \\
\text { for OSA } \\
\text { patients }\end{array}$ & $\begin{array}{l}\text { No patient with } \\
\text { OSA was cured }\end{array}$ \\
\hline $\begin{array}{l}\text { Craig et al. } \\
{[49]}\end{array}$ & $\begin{array}{l}\text { Pooled results } \\
\text { from three } \\
\text { double } \\
\text { blind } \\
\text { randomised } \\
\text { crossover } \\
\text { trials }\end{array}$ & $\begin{array}{l}42 \text { patients with } \\
\text { self-reported } \\
\text { daytime } \\
\text { somnolence } \\
\text { and impaired } \\
\text { sleep-OSA } \\
\text { patients } \\
\text { excluded }\end{array}$ & $\begin{array}{l}\text { Subjective } \\
\text { nasal } \\
\text { obstruction } \\
\text { and SPT } \\
\text { proven } \\
\text { NAR }\end{array}$ & $\begin{array}{l}\text { Nasal steroids od } \\
\text { (fluticasone } \\
200 \mathrm{mcg} \text {, } \\
\text { budesonide } \\
128 \mathrm{mcg} \text {, } \\
\text { flunisonide } \\
200 \mathrm{mcg} \text { ) for } \\
3 \text { weeks }\end{array}$ & $\begin{array}{l}\text { Mesured only in } \\
\text { fluticasone group: } \\
\text { no } \\
\text { polysomnographic } \\
\text { changes in AHI or } \\
\text { other sleep } \\
\text { parameters }\end{array}$ & $\begin{array}{l}\text { Decreased sleep } \\
\text { problems }(1.25 \\
\text { vs. } 1.69 ; \\
p=0.01) \\
\text { decreased } \\
\text { sleepiness } \\
(2.89 \text { vs. } 3.32 ; \\
p=0.02)\end{array}$ & $\begin{array}{l}\text { Significant } \\
\text { correlation } \\
\text { between changes } \\
\text { in nasal } \\
\text { congestion and } \\
\text { overall sleep } \\
\text { improvement }\end{array}$ \\
\hline $\begin{array}{l}\text { McLean } \\
\text { et al. [51] }\end{array}$ & $\begin{array}{l}\text { Double blind } \\
\text { crossover } \\
\text { study }\end{array}$ & $\begin{array}{r}\text { Ten OSA } \\
\text { patients }\end{array}$ & $\begin{array}{l}\text { Clinician } \\
\text { assessed } \\
\text { nasal } \\
\text { obstruction }\end{array}$ & $\begin{array}{l}\text { Topical } \\
\text { xylometazoline } \\
(0.2 \mathrm{mg} \text { twice }) \\
\text { and external } \\
\text { dilator strip for } \\
\text { one night }\end{array}$ & $\begin{array}{l}\text { AHI reduced by } 12, \\
\text { improved sleep } \\
\text { architecture }\end{array}$ & $\begin{array}{l}\text { No improvement } \\
\text { in daytime } \\
\text { sleepiness }\end{array}$ & $\begin{array}{l}\text { No correlation } \\
\text { between change } \\
\text { in nasal resitance } \\
\text { and AHI change. } \\
\text { Only one patient } \\
\text { had AHI }<15 \\
\text { after treatment }\end{array}$ \\
\hline $\begin{array}{l}\text { Kerr et al. } \\
{[50]}\end{array}$ & $\begin{array}{l}\text { Double blind } \\
\text { crossover } \\
\text { study }\end{array}$ & 10 OSA patients & $\begin{array}{l}\text { Six had } \\
\text { clinician } \\
\text { and patient } \\
\text { assessed } \\
\text { nasal } \\
\text { obstruction }\end{array}$ & $\begin{array}{l}\text { Topical } \\
\text { xylometazoline } \\
\text { before sleep } \\
\text { and internal } \\
\text { nasal dilator for } \\
\text { one night }\end{array}$ & $\begin{array}{l}\text { No change in AHI, } \\
\text { slightly reduced } \\
\text { arousal episodes }\end{array}$ & $\begin{array}{l}\text { Subjective } \\
\text { improvement } \\
\text { in sleep quality }\end{array}$ & \\
\hline $\begin{array}{l}\text { Clarenbach } \\
\text { et al. [52] }\end{array}$ & $\begin{array}{l}\text { Double blind } \\
\text { crossover } \\
\text { study }\end{array}$ & 12 OSA patients & $\begin{array}{l}\text { Subjective } \\
\text { nasal } \\
\text { obstruction }\end{array}$ & $\begin{array}{l}\text { Topical } \\
\text { xylometazoline } \\
0.15 \mathrm{mg} \text { od } \\
\text { before sleep for } \\
1 \text { week }\end{array}$ & No change in $\mathrm{AHI}$ & $\begin{array}{l}\text { No improvement } \\
\text { in sleep quality }\end{array}$ & $\begin{array}{l}\text { Significant } \\
\text { decrease in AHI } \\
\text { at the time of } \\
\text { maximal } \\
\text { decongestion }\end{array}$ \\
\hline
\end{tabular}

\section{Leukotriene antagonists}

A randomised double-blind crossover trial [53] assessing at the effects of montelukast on 31 patients with persistent allergic rhinitis and sleep disturbances found a significant effect of this leukotriene antagonist in reducing daytime somnolence as measured by Epworth sleepiness scale. However, none of the patients underwent polysomnography and this result has not been replicated in any other studies.

\section{Nasal dilators}

These devices increase the ability to breathe through the nose by dilating the narrow nasal valve area. There are two nasal dilators available: an externally applied Breathe Right ${ }^{\circledR}$ (CNS Inc; Bloomington, MN, USA) and an internal device Nozovent ${ }^{\circledR}$ (Prevancure $\mathrm{AB}$, Sweden). Four randomised non-blinded studies have been conducted with these devices and an improvement in snoring has been noted in three of them [54-57], but improvement in objective sleep parameters in only one study [54]. In this last study, however, at, [54] only patients with mild OSA were recruited, while the AHI decreased from 18 to 6.4 with no effect on daytime sleepiness. In all other studies no effects on AHI or daytime sleepiness was found. We feel that nasal dilators are generally not recommended as a primary treatment in patients with OSA but may be beneficial in simple snorers with nasal valve collapse. Their lack of side effects and their price makes them in any case worthy of trial in selected patients. If they help in improving symptoms then it may be worthwhile for the patient to be considered for definitive nasal valve surgery. 


\section{Surgical treatment}

As primary treatment

Nasal surgery is usually conducted to alter structural abnormalities present in primary snorers complaining of nasal obstruction in addition to snoring. There is another group of patients that may present to the rhinologist to improve the efficacy of their main treatment option of nasal continuous positive airway pressure (CPAP). Surgical procedures performed for SRBD include septoplasty/septorhinoplasty, functional endoscopic sinus surgery, turbinate reduction and nasal valve surgery.

Studies published in the 1980s and 1990s on effects of septoplasty on snoring demonstrated reduction in snoring by $50-75 \%$ [58-60]. In these studies, however, surgical outcomes were measured subjectively using questionnaires or visual analogue scales. Series, assessing the efficacy of nasal surgery (septoplasty, turbinectomy, and polypectomy) for OSA in a non-randomised study [61], suggested that normal cephalometry values of posterior airway space and mandibular plane to hyoid bone distances predicted surgical success. However, a more recent study by Virkkula et al. [62] suggested that snoring is not relieved by nasal surgery (septoplasty, septorhinoplasty and turbinate reduction surgery) despite an improvement in nasal resistance. This study conducted on forty Finnish patients presenting with snoring looked at the outcomes objectively using rhinomanometry, polysomnography and snoring intensity index. They concluded that the snoring time and intensity did not improve significantly in their patients, and that normal cephalometry did not predict a good response. In contrast to this Finnish study, studies from Korea [63] and Japan [64] assessing a different ethnic group showed a significant improvement in sleep parameters. This may appear to be the case if $p$ values are examined (e.g. reduction of the respiratory disturbance index (RDI) from 39 preoperatively to 29.4 postoperatively giving a $p$ value of 0.0001 as reported by Kim et al. [63]) but closer analysis of the study casts doubts on the clinical significance of this drop, if Sher's criteria (reduction of more than $50 \%$ in RDI or AHI or the actual value to be $<20$ ) are applied [65].

$\mathrm{Li}$ et al. [66, 67] addressed recently the role of nasal surgery in patients with snoring and OSA from two different perspectives. First, they looked at the efficacy of nasal surgery to relieve snoring [66] and tried to identify predictive factors concluding that the tonsil size affected the outcome of nasal surgery for snoring. Secondly, they looked at the important issue of improvement in QoL after nasal surgery alone for patients with OSA and nasal obstruction [67]. In this study, they evaluated QoL using generic and disease specific questionnaires. They utilised the short-form health survey (SF 36), snore outcome survey and a separate spouse/bed partner survey. They concluded that by correcting an obstructed nasal airway they were able to significantly improve disease specific and generic QoL thus, substantiating the role of nasal surgery in treating these patients. However, in spite of the significant improvement noted in QoL parameters, disappointingly, there was no statistically significant improvement in the objective polysomnographic data. This discrepancy between objective and subjective results is shared by numerous other similar studies following nasal surgery alone for SRBD. Verse et al. [68] studied a cohort of 26 patients of whom 19 had OSA and 7 were simple snorers. A variety of nasal surgical procedures including septorhinoplasty, septoplasty, sinus surgery and nasal valve surgery were carried out. They concluded that although nasal surgery significantly improved sleep quality and daytime somnolence, the surgical response rate in the apnoeic group was in the region of $15 \%$ based on objective parameters (AHI). Four of their patients had worsening of OSA in spite of improving arousal index in some of these. This paradoxical effect can be explained by the so-called "first night effect" (when the patient has the initial, preoperative, sleep study for the first time, he does not sleep well and as a result the study it may not reflect the true severity of the SRBD; but with the subsequent postoperative sleep study the patient is already accustomed to the attachment of various leads and hence, the recording on this occasion reflects more accurately the severity of the problem).

Morinaga et al. [69] assessed the way in which pharyngeal morphology affected the outcome of nasal surgery in patients with OSA and nasal obstruction. The pharyngeal morphological features they looked at included tonsil size, Mallampati score, narrowness of fauces and the retroglossal dimension. They concluded that a favourable surgical outcome was seen in individuals who had a high-positioned soft palate and/or in those with a wide retroglossal space. Unlike Li et al. [66] they did not feel that the tonsil size affected the outcome of nasal surgery. However, the most important, and only randomised control trial was performed by the group of Koutsourelakis in Athens in 2007 [70], who assigned 49 patients with OSA and deviated nasal septum to either septoplasty or sham surgery and found that despite improvements in nasal patency as measured subjectively and objectively, there was no change in AHI or daytime sleepiness as assessed by Epworth Sleepiness Scale. Interestingly, in the surgical group there were $4(14.8 \%)$ responders (using Sher's criteria of reduction of $\mathrm{AHI}$ by more than $50 \%$ ), however, only one patient was disease-free $(\mathrm{AHI}<5)$. In conclusion, nasal surgery may improve QoL and snoring in a subgroup of patients with mild SDB and septal deviation. Although nasal surgery is certainly not an effective general treatment 
for OSA, further studies may better define carefully selected subgroups in which it may be of benefit.

\section{As adjunctive to CPAP}

The second group of patients that may be considered for nasal surgery are those who have failed CPAP therapy. The treatment of choice for moderate or severe OSA is CPAP but unfortunately it is frequently poorly tolerated with compliance rates less than 70\% [71]. One of the reasons that patients may find CPAP so uncomfortable is either pre-existing structural nasal obstruction or CPAPinduced rhinitis. More than $50 \%$ of CPAP users complain of significant nasal symptoms, including nasal congestion, rhinorrhea, nasal dryness and sneezing [72]. Thus, it is vital that patients who do not comply with or adhere poorly to CPAP therapy should undergo detailed evaluation of their upper airway to identify obstructive pathology that may be surgically correctable. This may lead to a reduction in the CPAP pressure and, therefore, improve the compliance of this form of therapy. Powell [73] demonstrated this in a group of CPAP patients undergoing radiofrequency turbinate reduction. Patients in this study reported a subjective improvement in nasal obstruction which in turn was linked to improved CPAP use. Similarly, Friedman et al. [74] showed a significant decrease in CPAP titration levels following nasal surgery. In this study, reduction of pressure requirement for CPAP therapy was noted in patients with mild, moderate and severe OSA. The mean reduction of CPAP titration level was from $9.3 \mathrm{cmH}_{2} \mathrm{O}$ preoperatively to $6.7 \mathrm{cmH}_{2} \mathrm{O}$ postoperatively. This reduction in pressure would certainly help in improving the CPAP compliance.

\section{Conclusion}

It is now well recognised that improving nasal resistance medically, surgically or with the use of dilators can improve sleep quality; however, significant improvement in objective sleep parameters remain to be proven. Although there is no role for nasal surgery as single treatment for OSA, it is quite useful in improving symptoms in simple snorers and potentially useful as part of multilevel surgery in many patients with SRBD. In CPAP failures if upper airway evaluation demonstrates an obstructive nasal passage then treating this certainly improves CPAP compliance and adherence. In general, patients who responds positively to medical treatment or nasal dilators may be candidates for nasal surgical intervention, taking into account the limitations described.
Key points

1. Mechanisms through which nasal obstruction can lead or contribute to sleep apnoeas include the Starling resistor model, shunting of airflow through an unstable oral airway, blocking of the nasal respiratory reflex and reduced NO production and delivery.

2. Patients with self-reported nocturnal nasal obstruction are up to threefold more likely to snore and suffer from daytime somnolence.

3. Nasal steroids have been proven to improve subjective quality of sleep in patients with allergic rhinitis, but are not an effective treatment for adults with OSA.

4. Surgery to improve nasal patency is not indicated as primary treatment in patients with OSA, however, in selected patients with simple snoring it may reduce snoring and improve QoL.

5. In patients with OSA and nasal obstruction using CPAP, nasal surgery may reduce pressure requirements and improve compliance.

Open Access This article is distributed under the terms of the Creative Commons Attribution Noncommercial License which permits any noncommercial use, distribution, and reproduction in any medium, provided the original author(s) and source are credited.

\section{References}

1. Hippocrates, Freind J De morbis popularibus 1717

2. Tsai W, Flemons W, Whitelaw W, Remmers J (1999) A comparison of apnea-hypopnea indices derived from different definitions of hypopnea. Am J Respir Crit Care Med 159(1):43-48

3. Medicine AAOS, American Academy of Sleep Medicine (2001) ISBN 0-9657220-1-5, PDF-complete, Library of Congress Catalog No. 97-71405. In: The international classification of sleep disorders, revised: diagnostic and coding manual; 2001. Available at: http://web.archive.org/web/20070927034423/http:// www.absm.org/PDF/ICSD.pdf (Accessed July 3, 2010)

4. Young T, Palta M, Dempsey J et al (1993) The occurrence of sleep-disordered breathing among middle-aged adults. N Engl J Med 328(17):1230-1235

5. Punjabi NM, Caffo BS, Goodwin JL et al (2009) Sleep-disordered breathing and mortality: a prospective cohort study. PLoS Med 6(8):e1000132

6. Schwab RJ, Gefter WB, Hoffman EA, Gupta KB, Pack AI (1993) Dynamic upper airway imaging during awake respiration in normal subjects and patients with sleep disordered breathing. Am Rev Respir Dis 148(5):1385-1400

7. Osborne JE, Osman EZ, Hill PD, Lee BV, Sparkes C (1999) A new acoustic method of differentiating palatal from non-palatal snoring. Clin Otolaryngol Allied Sci 24(2):130-133

8. Kotecha BT, Hannan SA, Khalil HMB, Georgalas C, Bailey P (2007) Sleep nasendoscopy: a 10-year retrospective audit study. Eur Arch Otorhinolaryngol 264(11):1361-1367

9. Skatvedt O (1995) Continuous pressure measurements during sleep to localize obstructions in the upper airways in heavy snorers and patients with obstructive sleep apnea syndrome. Eur Arch Otorhinolaryngol 252(1):11-14 
10. Georgalas C, Garas G, Hadjihannas E, Oostra A (2010) Assessment of obstruction level and selection of patients for obstructive sleep apnoea surgery: an evidence-based approach. J Laryngol Otol 124(1):1-9

11. Olsen KD, Kern EB, Westbrook PR (1981) Sleep and breathing disturbance secondary to nasal obstruction. Otolaryngol Head Neck Surg 89(5):804-810

12. Cole P, Haight JS (1984) Mechanisms of nasal obstruction in sleep. Laryngoscope 94(12 Pt 1):1557-1559

13. Ferris BG, Mead J, Opie LH (1964) Partitioning of respiratory flow resistance in man. J Appl Physiol 19:653-658

14. Smith PL, Wise RA, Gold AR, Schwartz AR, Permutt S (1988) Upper airway pressure-flow relationships in obstructive sleep apnea. J Appl Physiol 64(2):789-795

15. Park SS (1993) Flow-regulatory function of upper airway in health and disease: a unified pathogenetic view of sleep-disordered breathing. Lung 171(6):311-333

16. Rundcrantz H (1969) Postural variations of nasal patency. Acta Otolaryngol 68(5):435-443

17. Fitzpatrick MF, McLean H, Urton AM et al (2003) Effect of nasal or oral breathing route on upper airway resistance during sleep. Eur Respir J 22(5):827-832

18. Fitzpatrick MF, Driver HS, Chatha N, Voduc N, Girard AM (2003) Partitioning of inhaled ventilation between the nasal and oral routes during sleep in normal subjects. J Appl Physiol 94(3):883-890

19. Meurice JC, Marc I, Carrier G, Sériès F (1996) Effects of mouth opening on upper airway collapsibility in normal sleeping subjects. Am J Respir Crit Care Med 153(1):255-259

20. McNicholas WT, Coffey M, Boyle T (1993) Effects of nasal airflow on breathing during sleep in normal humans. Am Rev Respir Dis 147(3):620-623

21. Douglas NJ, White DP, Weil JV, Zwillich CW (1983) Effect of breathing route on ventilation and ventilatory drive. Respir Physiol 51(2):209-218

22. White DP, Cadieux RJ, Lombard RM et al (1985) The effects of nasal anesthesia on breathing during sleep. Am Rev Respir Dis 132(5):972-975

23. Berry RB, Kouchi KG, Bower JL, Light RW (1995) Effect of upper airway anesthesia on obstructive sleep apnea. Am J Respir Crit Care Med 151(6):1857-1861

24. Lundberg JO (1996) Airborne nitric oxide: inflammatory marker and aerocrine messenger in man. Acta Physiol Scand Suppl 633:1-27

25. Blitzer ML, Loh E, Roddy MA, Stamler JS, Creager MA (1996) Endothelium-derived nitric oxide regulates systemic and pulmonary vascular resistance during acute hypoxia in humans. J Am Coll Cardiol 28(3):591-596

26. Djupesland PG, Chatkin JM, Qian W et al (1999) Aerodynamic influences on nasal nitric oxide output measurements. Acta Otolaryngol 119(4):479-485

27. Haight JSJ, Djupesland PG (2003) Nitric oxide (NO) and obstructive sleep apnea (OSA). Sleep Breath 7(2):53-62

28. Suratt PM, Turner BL, Wilhoit SC (1986) Effect of intranasal obstruction on breathing during sleep. Chest 90(3):324-329

29. Lavie P, Fischel N, Zomer J, Eliaschar I (1983) The effects of partial and complete mechanical occlusion of the nasal passages on sleep structure and breathing in sleep. Acta Otolaryngol 95(1-2):161-166

30. Cassisi NJ, Biller HF, Ogura JH (1971) Changes in arterial oxygen tension and pulmonary mechanics with the use of posterior packing in epistaxis: a preliminary report. Laryngoscope 81(8):1261-1266

31. Slocum CW, Maisel RH, Cantrell RW (1976) Arterial blood gas determination in patients with anterior packing. Laryngoscope 86(6):869-873
32. Ogretmenoglu O, Yilmaz T, Rahimi K, Aksöyek S (2002) The effect on arterial blood gases and heart rate of bilateral nasal packing. Eur Arch Otorhinolaryngol 259(2):63-66

33. Young T, Finn L, Palta M (2001) Chronic nasal congestion at night is a risk factor for snoring in a population-based cohort study. Arch Intern Med 161(12):1514-1519

34. Virkkula P, Bachour A, Hytönen M et al (2005) Patient- and bed partner-reported symptoms, smoking, and nasal resistance in sleep-disordered breathing. Chest 128(4):2176-2182

35. Lofaso F, Coste A, d'Ortho MP et al (2000) Nasal obstruction as a risk factor for sleep apnoea syndrome. Eur Respir J 16(4): 639-643

36. Miljeteig H, Hoffstein V, Cole P (1992) The effect of unilateral and bilateral nasal obstruction on snoring and sleep apnea. Laryngoscope 102(10):1150-1152

37. Miljeteig H, Savard P, Mateika S et al (1993) Snoring and nasal resistance during sleep. Laryngoscope 103(8):918-923

38. Settipane RA, Charnock DR (2007) Epidemiology of rhinitis: allergic and nonallergic. Clin Allergy Immunol 19:23-34

39. Ferguson BJ (2004) Influences of allergic rhinitis on sleep. Otolaryngol Head Neck Surg 130(5):617-629

40. Krouse HJ, Davis JE, Krouse JH (2002) Immune mediators in allergic rhinitis and sleep. Otolaryngol Head Neck Surg 126(6): 607-613

41. McNicholas WT, Tarlo S, Cole P et al (1982) Obstructive apneas during sleep in patients with seasonal allergic rhinitis. Am Rev Respir Dis 126(4):625-628

42. Stuck BA, Czajkowski J, Hagner A et al (2004) Changes in daytime sleepiness, quality of life, and objective sleep patterns in seasonal allergic rhinitis: a controlled clinical trial. J Allergy Clin Immunol 113(4):663-668

43. Kalpaklioğlu AF, Kavut AB, Ekici M (2009) Allergic and nonallergic rhinitis: the threat for obstructive sleep apnea. Ann Allergy Asthma Immunol 103(1):20-25

44. McNicholas WT (2008) The nose and OSA: variable nasal obstruction may be more important in pathophysiology than fixed obstruction. Eur Respir J 32(1):3-8

45. Craig TJ, Teets S, Lehman EB, Chinchilli VM, Zwillich C (1998) Nasal congestion secondary to allergic rhinitis as a cause of sleep disturbance and daytime fatigue and the response to topical nasal corticosteroids. J Allergy Clin Immunol 101(5):633-637

46. Craig TJ, Mende C, Hughes K et al (2003) The effect of topical nasal fluticasone on objective sleep testing and the symptoms of rhinitis, sleep, and daytime somnolence in perennial allergic rhinitis. Allergy Asthma Proc 24(1):53-58

47. Kiely JL, Nolan P, McNicholas WT (2004) Intranasal corticosteroid therapy for obstructive sleep apnoea in patients with coexisting rhinitis. Thorax 59(1):50-55

48. Hughes K, Glass C, Ripchinski M et al (2003) Efficacy of the topical nasal steroid budesonide on improving sleep and daytime somnolence in patients with perennial allergic rhinitis. Allergy 58(5):380-385

49. Craig TJ, Hanks CD, Fisher LH (2005) How do topical nasal corticosteroids improve sleep and daytime somnolence in allergic rhinitis? J Allergy Clin Immunol 116(6):1264-1266

50. Kerr P, Millar T, Buckle P, Kryger M (1992) The importance of nasal resistance in obstructive sleep apnea syndrome. J Otolaryngol 21(3):189-195

51. McLean HA, Urton AM, Driver HS et al (2005) Effect of treating severe nasal obstruction on the severity of obstructive sleep apnoea. Eur Respir J 25(3):521-527

52. Clarenbach CF, Kohler M, Senn O, Thurnheer R, Bloch KE (2008) Does nasal decongestion improve obstructive sleep apnea? J Sleep Res 17(4):444-449

53. Santos CB, Hanks C, McCann J et al (2008) The role of montelukast on perennial allergic rhinitis and associated sleep 
disturbances and daytime somnolence. Allergy Asthma Proc 29(2):140-145

54. Höijer U, Ejnell H, Hedner J, Petruson B, Eng LB (1992) The effects of nasal dilation on snoring and obstructive sleep apnea. Arch Otolaryngol Head Neck Surg 118(3):281-284

55. Pevernagie D, Hamans E, Van Cauwenberge P, Pauwels R (2000) External nasal dilation reduces snoring in chronic rhinitis patients: a randomized controlled trial. Eur Respir J 15(6): 996-1000

56. Djupesland PG, Skatvedt O, Borgersen AK (2001) Dichotomous physiological effects of nocturnal external nasal dilation in heavy snorers: the answer to a rhinologic controversy? Am J Rhinol 15(2):95-103

57. Bahammam AS, Tate R, Manfreda J, Kryger MH (1999) Upper airway resistance syndrome: effect of nasal dilation, sleep stage, and sleep position. Sleep 22(5):592-598

58. Low WK (1994) Can snoring relief after nasal septal surgery be predicted? Clin Otolaryngol Allied Sci 19(2):142-144

59. Ellis PD, Harries ML, Ffowcs Williams JE, Shneerson JM (1992) The relief of snoring by nasal surgery. Clin Otolaryngol Allied Sci 17(6):525-527

60. Fairbanks DN (1985) Effect of nasal surgery on snoring. South Med J 78(3):268-270

61. Sériès F, St Pierre S, Carrier G (1993) Surgical correction of nasal obstruction in the treatment of mild sleep apnoea: importance of cephalometry in predicting outcome. Thorax 48(4):360-363

62. Virkkula P, Bachour A, Hytönen M et al (2006) Snoring is not relieved by nasal surgery despite improvement in nasal resistance. Chest 129(1):81-87

63. Kim ST, Choi JH, Jeon HG et al (2004) Polysomnographic effects of nasal surgery for snoring and obstructive sleep apnea. Acta Otolaryngol 124(3):297-300

64. Nakata S, Noda A, Yasuma F et al (2008) Effects of nasal surgery on sleep quality in obstructive sleep apnea syndrome with nasal obstruction. Am J Rhinol 22(1):59-63
65. Sher AE, Schechtman KB, Piccirillo JF (1996) The efficacy of surgical modifications of the upper airway in adults with obstructive sleep apnea syndrome. Sleep 19(2):156-177

66. Li H, Lee L, Wang P et al (2008) Nasal surgery for snoring in patients with obstructive sleep apnea. Laryngoscope 118(2): 354-359

67. Li H, Lin Y, Chen $\mathrm{N}$ et al (2008) Improvement in quality of life after nasal surgery alone for patients with obstructive sleep apnea and nasal obstruction. Arch Otolaryngol Head Neck Surg 134(4):429-433

68. Verse T, Maurer JT, Pirsig W (2002) Effect of nasal surgery on sleep-related breathing disorders. Laryngoscope 112(1):64-68

69. Morinaga M, Nakata S, Yasuma F et al (2009) Pharyngeal morphology: a determinant of successful nasal surgery for sleep apnea. Laryngoscope 119(5):1011-1016

70. Koutsourelakis I, Georgoulopoulos G, Perraki E et al (2008) Randomised trial of nasal surgery for fixed nasal obstruction in obstructive sleep apnoea. Eur Respir J 31(1):110-117

71. McArdle N, Devereux G, Heidarnejad H et al (1999) Long-term use of CPAP therapy for sleep apnea/hypopnea syndrome. Am J Respir Crit Care Med 159(4 Pt 1):1108-1114

72. Hoffstein V, Viner S, Mateika S, Conway J (1992) Treatment of obstructive sleep apnea with nasal continuous positive airway pressure. Patient compliance, perception of benefits, and side effects. Am Rev Respir Dis 145(4 Pt 1):841-845

73. Powell NB, Zonato AI, Weaver EM et al (2001) Radiofrequency treatment of turbinate hypertrophy in subjects using continuous positive airway pressure: a randomized, double-blind, placebocontrolled clinical pilot trial. Laryngoscope 111(10):1783-1790

74. Friedman M, Tanyeri H, Lim JW et al (2000) Effect of improved nasal breathing on obstructive sleep apnea. Otolaryngol Head Neck Surg 122(1):71-74 